\title{
Impact of fatty acid structure on CALB-catalyzed esterification of glucose
}

\author{
Dounia Arcens ${ }^{\mathrm{a}}$, Etienne Grau ${ }^{\mathrm{a}}$, Stéphane Grelier ${ }^{\mathrm{a}}$, Henri Cramail$^{* a}$ and Frédéric Peruch*a \\ ${ }^{a}$ Univ. Bordeaux, CNRS, Bordeaux INP, LCPO, UMR 5629, F-33600, Pessac, France \\ e-mail: peruch@enscbp.fr ; cramail@enscbp.fr
}

\section{Funding}

This work was performed, in partnership with the SAS PIVERT, within the frame of the French Institute for the Energy Transition (Institut pour la Transition Energétique - ITE) P.I.V.E.R.T. (www.institut-pivert.com) selected as an Investment for the Future (“Investissements d'Avenir"). This work was supported, as part of the Investments for the Future, by the French Government under the reference ANR-001-01. The authors would also thank Equipex Xyloforest ANR-10-EQPX-16 XYLOFOREST for HPLC.

\begin{abstract}
:
Enzymatic synthesis of fatty acid glucose esters from different fatty acyl donors were performed via enzymatic catalysis in the presence of CALB, using acetonitrile as the solvent. The acyl donor nature (fatty acid or fatty acid vinyl ester) and structure were varied. Lower reaction rates and lower conversions were obtained with fatty acids in comparison to their corresponding vinyl esters. Moreover, the acyl donor with the longest chain length gave the highest conversions. The presence of unsaturation on the acyl donor chain was also shown to be detrimental to the conversion.
\end{abstract}

\section{Introduction}

Glycolipids, also known as fatty acid sugar esters (FASE), are molecules composed of a fatty alkyl chain and a saccharide moiety. These non-ionic amphiphilic molecules are generally biodegradable and biocompatible $(1 ; 2)$ and are therefore molecules of great interest for markets such as detergents, 
$(3 ; 4 ; 5)$ cosmetics $(6 ; 7)$ and food $(3 ; 4 ; 8 ; 9)$ as emulsifiers, emollients or conservatives, respectively. Highly substituted sucrose esters have been commercialized by Procter \& Gamble as substitutes for resins in paint formulations, while low-substituted sucrose esters are used as additives for food industry, known as 'E473'. Depending on the fatty chain functionalization, glycolipids properties can also be tuned to exhibit antioxidant, $(10)$ antimicrobial, $(11 ; 12)$ or antibacterial behavior (13). Some FASE have also been proved to be gelating agents. (14)

FASE synthesis is usually performed in the presence of alkaline catalysts such as potassium carbonate, potassium lactate, or metallic sodium. Besides requiring the use of toxic solvents and high temperatures, this route is generally not selective and mixtures of esters with different substitution degrees are obtained. (15) Enzymatic catalysis offers an interesting alternative for glycolipids synthesis. Indeed, esterases from group EC3.1, such as lipases and proteases, can catalyze FASE synthesis under milder and less toxic conditions than chemical catalysts. In particular, lipases are generally strictly selective toward primary alcohols, which leads to FASE of controlled structure. Hence, lipase-catalyzed FASE synthesis has encountered a large interest in the last decades. Nevertheless, while extensively studied, a lot of contradictions exist in the literature concerning the influence of the main reaction parameters. One of the most typical examples concerns the influence of the fatty acid or ester chain length on its conversion into glycolipid. Ghoul and coll. investigated the esterification of fructose with FAs having chain lengths from C8 to C18 in 2-methyl-2-butanol. The authors observed an increase of final conversions into FASEs while increasing the acyl donor chain length. (16) Schmid and coll. investigated the Candida antarctica Lipase B (CALB)-catalyzed glucose esterification in solid phase, composed of glucose, FA (C6 to C18), and about 100\%-300\% of organic solvent as adjuvant $(17 ; 18)$, and came to the same conclusions. On the contrary, Pedersen and coll. studied the esterification of several disaccharides with FAs (C4 to C12) and observed higher initial conversion rates and higher conversions for shorter chains. (19) Lin and coll. studied glucose acylation by vinyl diesters of different chain lengths (C4 to C10) and also observed the highest conversions into glycolipid for shorter chains. (20) Those papers studied the influence of chain length 
on either fatty acids, vinyl esters, or methyl esters as acyl donors but, to our knowledge, no existing study compares results obtained from direct esterification or trans-esterification. In our previous work, (21) we described an exhaustive study of the influence of the lipase, the solvent and the temperature on the synthesis of 6-O-glucose palmitate. It was shown that a full acylation of glucose was possible within 40 hours in anhydrous acetonitrile at $45^{\circ} \mathrm{C}$, in the presence of only 5 wt- $\%$ of CALB. In this paper, we investigate the effect of the acyl donor chain length on FASE synthesis catalyzed by CALB. Based on our previous results, reactions were performed in anhydrous acetonitrile at $45^{\circ} \mathrm{C}$. Both saturated fatty acids (FA, C8 to C18) and fatty acid vinyl esters (FAVE, $\mathrm{C} 4$ to $\mathrm{C} 18$ ) were used as acyl donors and their influence on reaction kinetics and final conversion into FASE was evaluated. The influence of the presence of unsaturations and their configuration was also investigated.

\section{Material and methods}

\subsection{Material}

Vinyl butyrate, vinyl hexanoate, vinyl decanoate and vinyl palmitate were purchased from TCI Europe. Vinyl oleate was provided by Iterg (Pessac, France). Octanoic acid, lauric acid, myristic acid, palmitic acid, stearic acid, oleic acid and lipase B from Candida antarctica immobilized on acrylic beads were purchased from Sigma Aldrich. Elaidic acid, linoleic acid, and linoleaidic acid were purchased from Nu-Chek Prep. Anhydrous glucose was purchased from Fluka. Acetonitrile (Fluka, HPLC grade) was dried over alumina column. All the other compounds were used as received.

\subsection{Characterization methods}

NMR experiments were performed at $298 \mathrm{~K}$ on a Bruker Avance 400 spectrometer operating at 400MHz. Deuterated DMSO was used as solvent.

HPLC analysis was performed on a HPLC apparatus with an evaporating light scattering detector (ELSD, Varian 380-LC) and a Prevail carbohydrate ES $5 \mu$ column. The evaporator and nebulizer temperatures were set at $90^{\circ} \mathrm{C}$ and $40^{\circ} \mathrm{C}$, respectively. $50 \mu \mathrm{L}$ of the samples were injected. The eluent 
was a solution of 75/25/5 v/v/v methanol/acetonitrile/water with a flow rate of $0.5 \mathrm{~mL} \cdot \mathrm{min}^{-1}$.

2.3 Synthetic procedures

\subsubsection{Synthesis of fatty acid vinyl esters (FAVEs)}

Vinyl esters from octanoic acid, lauric acid, myristic acid, stearic acid, elaidic acid, linoleic acid and linoleaidic acid were synthesized according to the procedure described by Vilela and coll. (22)

Saturated vinyl esters: Yield: 50-70 \%; ${ }^{1} \mathrm{H}$ NMR (DMSO, $\left.298 \mathrm{~K}\right): 7.28\left(1 \mathrm{H}, \mathrm{dd}, \mathbf{C H}=\mathrm{CH}_{2}\right), 5.34(2 \mathrm{H}$, $\mathbf{C H}=\mathbf{C H}), 4.86\left(1 \mathrm{H}, \mathrm{dd}, \mathbf{C H}_{2}=\mathrm{CH}\right), 4.56\left(1 \mathrm{H}, \mathrm{dd}, \mathbf{C H}_{2}=\mathrm{CH}\right), 2.38\left(2 \mathrm{H}, \mathrm{t}, \mathbf{C H}_{2}-\mathrm{CO}\right), 1.65(2 \mathrm{H}, \mathrm{q}$, $\left.\mathbf{C H}_{2}-\mathrm{CH}_{2}-\mathrm{CO}\right), 1.17-1.39$ (m, alkyl chain $\left.\mathrm{CH}_{2}\right), 0.88\left(3 \mathrm{H}, \mathrm{t}, \mathrm{CH}_{3}\right)$

Vinyl elaidate: Yield: $77 \%$; ${ }^{1} \mathrm{H}$ NMR (DMSO, $\left.298 \mathrm{~K}\right): 7.29\left(1 \mathrm{H}, \mathrm{dd}, \mathbf{C H}=\mathrm{CH}_{2}\right), 5.38(2 \mathrm{H}, \mathrm{m}$, $\mathbf{C H}=\mathbf{C H}), 4.86\left(1 \mathrm{H}, \mathrm{dd}, \mathbf{C H}_{2}=\mathrm{CH}\right), 4.56\left(1 \mathrm{H}, \mathrm{dd}, \mathbf{C H}_{2}=\mathrm{CH}\right), 2.38\left(2 \mathrm{H}, \mathrm{t}, \mathbf{C H}_{2}-\mathrm{CO}\right), 1.96(4 \mathrm{H}, \mathrm{m}$, $\left.\mathbf{C H}_{2}-\mathrm{CH}=\mathrm{CH}\right) 1.65\left(2 \mathrm{H}, \mathrm{q}, \mathbf{C H}_{2}-\mathrm{CH}_{2}-\mathrm{CO}\right), 1.20-1.30\left(18 \mathrm{H}, \mathrm{m}\right.$, alkyl chain $\left.\mathrm{CH}_{2}\right), 0.88\left(3 \mathrm{H}, \mathrm{t}, \mathrm{CH}_{3}\right)$ Vinyl linoleate: Yield: $70 \%$; ${ }^{1} \mathrm{H}$ NMR (DMSO, $\left.298 \mathrm{~K}\right): 7.28\left(1 \mathrm{H}, \mathrm{dd}, \mathbf{C H}=\mathrm{CH}_{2}\right), 5.36(4 \mathrm{H}, \mathrm{m}$, $\mathrm{CH}=\mathrm{CH}), 4.86\left(1 \mathrm{H}, \mathrm{dd}, \mathbf{C H}_{2}=\mathrm{CH}\right), 4.56\left(1 \mathrm{H}, \mathrm{dd}, \mathbf{C H}_{2}=\mathrm{CH}\right), 2,77\left(2 \mathrm{H}, \mathrm{t}, \mathrm{CH}=\mathbf{C H}_{2}=\mathrm{CH}\right), 2.38(2 \mathrm{H}$, t, $\left.\mathbf{C H}_{2}-\mathrm{CO}\right), 2.04$ (4H, m, $\left.\mathbf{C H}_{2}-\mathrm{CH}=\mathrm{CH}\right), 1.66\left(2 \mathrm{H}, \mathrm{q}, \mathbf{C H}_{2}-\mathrm{CH}_{2}-\mathrm{CO}\right), 1.19-1.36$ (14H, m, alkyl chain $\left.\mathrm{CH}_{2}\right), 0.89\left(3 \mathrm{H}, \mathrm{t}, \mathrm{CH}_{3}\right)$,

Vinyl linoleaidate: Yield: $74 \%$; ${ }^{1} \mathrm{H}$ NMR (DMSO, $\left.298 \mathrm{~K}\right): 7.28\left(1 \mathrm{H}, \mathrm{dd}, \mathbf{C H}=\mathrm{CH}_{2}\right), 5.40(4 \mathrm{H}, \mathrm{m}$, $\mathrm{CH}=\mathrm{CH}), 4.86\left(1 \mathrm{H}, \mathrm{dd}, \mathbf{C H}_{2}=\mathrm{CH}\right), 4.56\left(1 \mathrm{H}, \mathrm{dd}, \mathbf{C H}_{2}=\mathrm{CH}\right), 2,67\left(2 \mathrm{H}, \mathrm{t}, \mathrm{CH}=\mathbf{C H}_{2}=\mathrm{CH}\right), 2.38(2 \mathrm{H}$, t, $\left.\mathbf{C H}_{2}-\mathrm{CO}\right), 1,99\left(4 \mathrm{H}, \mathrm{m}, \mathbf{C} \mathbf{C H}_{2}-\mathrm{CH}=\mathrm{CH}\right), 1.65\left(2 \mathrm{H}, \mathrm{q}, \mathbf{C H}_{2}-\mathrm{CH}_{2}-\mathrm{CO}\right), 1.19-1.39$ (14H, m, alkyl chain $\left.\mathrm{CH}_{2}\right), 0.88\left(3 \mathrm{H}, \mathrm{t}, \mathrm{CH}_{3}\right)$

\subsubsection{Synthesis of glycolipids}

0.9 mmol of either FA or FAVE and 0.9 mmol of glucose were poured in an oven-dried Schlenk with $10 \mathrm{~mL}$ of anhydrous acetonitrile under argon. $20 \mathrm{mg}$ of immobilized CALB were therefore added. The reaction was carried under a magnetic stirring of $250 \mathrm{rpm}$ at $45^{\circ} \mathrm{C}$ heated by a thermoset oil bath. Reactions were followed by collecting $0.2 \mathrm{~mL}$ aliquots and the compounds proportions were determined by ${ }^{1} \mathrm{H}$ NMR (See Supplementary Information). In all cases, only the OH6 of glucose was esterified, secondary alcohols remaining untouched. At the end of the reaction, acetonitrile was 
evaporated. THF was poured in the crude mixture and the obtained mixture was filtered under vacuum in order to remove the lipase and most of the glucose. The soluble part was evaporated. The obtained solid was dispersed into water then filtrated on a Büchner in order to remove traces of glucose. 5$10 \mathrm{~mL}$ of acetone was then added to dissolve the unreacted fatty chains and the suspension was filtrated again. The remaining insoluble white powder was characterized by ${ }^{1} \mathrm{H}$ NMR spectroscopy and was found to be pure 6O-glucoester. Glucoesters were isolated with yields of 50-90\% depending on the chain length. Each glycolipid synthesis was performed in duplicates.

\section{Results and discussion}

3.1 Influence of acyl donor chain length

Enzyme-catalyzed esterification reactions were first carried out starting from glucose and saturated FAs with chain lengths from C8 to C18 (Scheme 1).

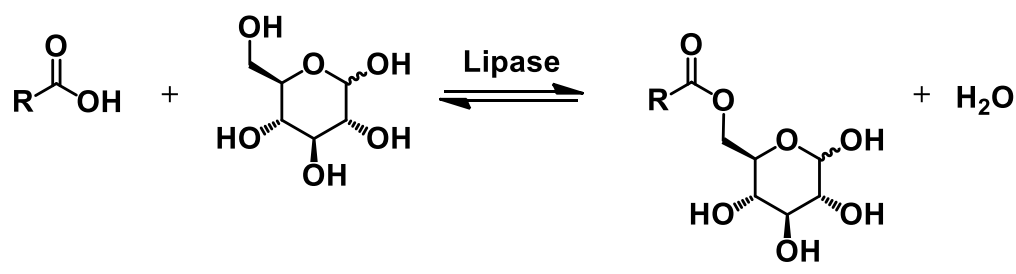

\section{Scheme 1: FASE synthesis from fatty acid and glucose}

Enzymatic acylation of glucose was then examined using FAVEs with chain lengths from C4 to C18.

(Scheme 2) FAVEs are also good candidates for transesterification reactions as transesterifications are much faster than FAs esterifications and lead to higher conversion rates. (23) Indeed, on the contrary to classical esterification using FAs, there is no need to shift the equilibrium, as released vinyl alcohol is immediately converted to acetaldehyde, making the reaction irreversible (reaction 1 on Scheme 2). Therefore, because of the presence of residual water in the reaction medium, the enzyme can also catalyze FAVE hydrolysis (reaction 2 on Scheme 2), which is also irreversible. An equilibrium can then take place between the so-formed FA and the corresponding glycolipid (reaction 3 on Scheme 2). 


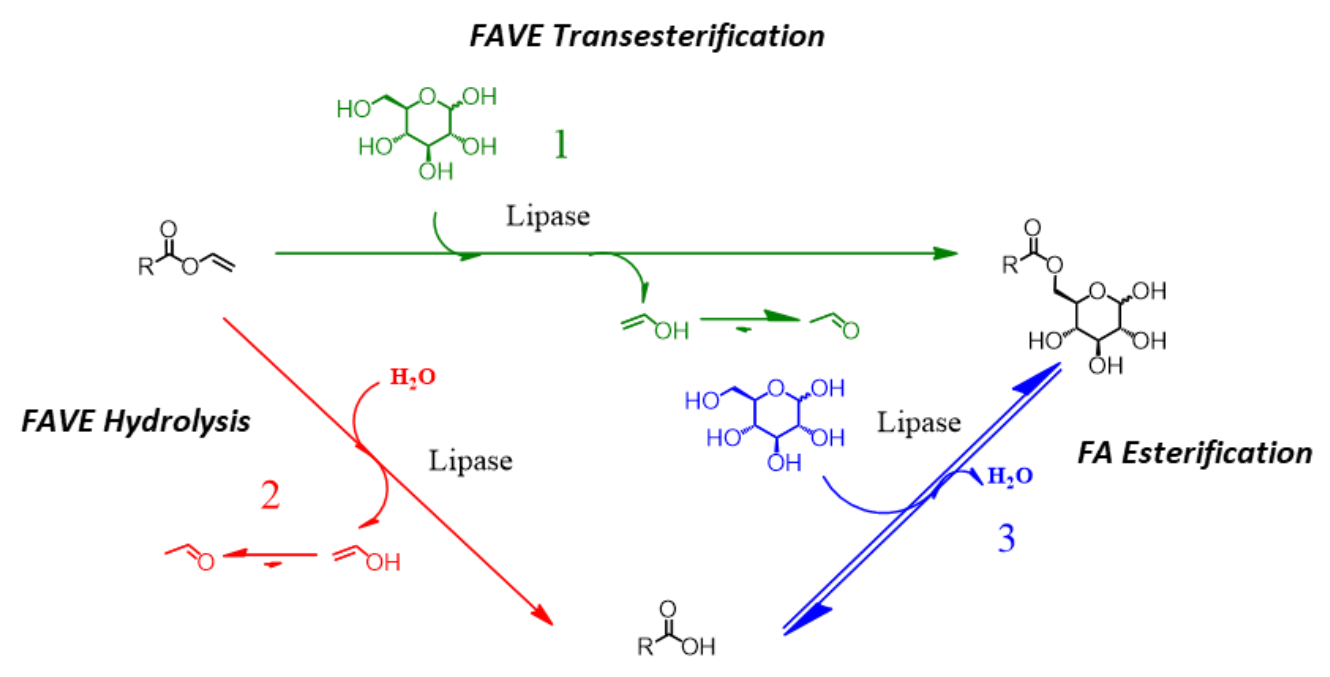

Scheme 2: FASE synthesis from vinyl ester and glucose

All the reactions were carried out at $45^{\circ} \mathrm{C}$ during 72 hours and were monitored using ${ }^{1} \mathrm{H}$ NMR. Plots of 6-O-glucose monoester conversion versus time for each FA and each FAVE are shown in Figure 1 and Figure 2, respectively. Glucose acylation initial rates have been calculated from those plots and are exposed in Table 1.

\begin{tabular}{|c|c|c|c|c|}
\hline & $\begin{array}{c}\text { Acylation after } \\
7 \text { days }(\%)\end{array}$ & $\begin{array}{l}\text { FA } \\
\text { Initial FASE formation rate } \\
\left(\mu \text { mol.min }{ }^{-1} \cdot \mathrm{g}^{-1} \text { CALB }\right. \\
\text { beads })\end{array}$ & $\begin{array}{c}\text { Acylation after } \\
3 \text { days (\%) }\end{array}$ & $\begin{array}{l}\text { FAVE } \\
\text { Initial FASE formation rate } \\
\left(\mu \text { mol.min }{ }^{-1} \cdot \mathrm{g}^{-1} \text { CALB }\right. \\
\text { beads })\end{array}$ \\
\hline $\mathrm{C} 4$ & - & - & 81 & 24 \\
\hline C6 & - & - & 83 & 44 \\
\hline C8 & 9 & 6 & 55 & 33 \\
\hline $\mathrm{C} 10$ & 17 & 5 & 42 & 35 \\
\hline $\mathrm{C} 12$ & 21 & 5 & 75 & 29 \\
\hline $\mathrm{C} 14$ & 46 & 6 & 100 & 29 \\
\hline C16 & 55 & 7 & 100 & 28 \\
\hline C18 & 65 & 12 & 100 & 30 \\
\hline
\end{tabular}


Table 1 - Final conversions into FASEs and glucose initial conversion rates depending on FA or FAVEs chain lengths

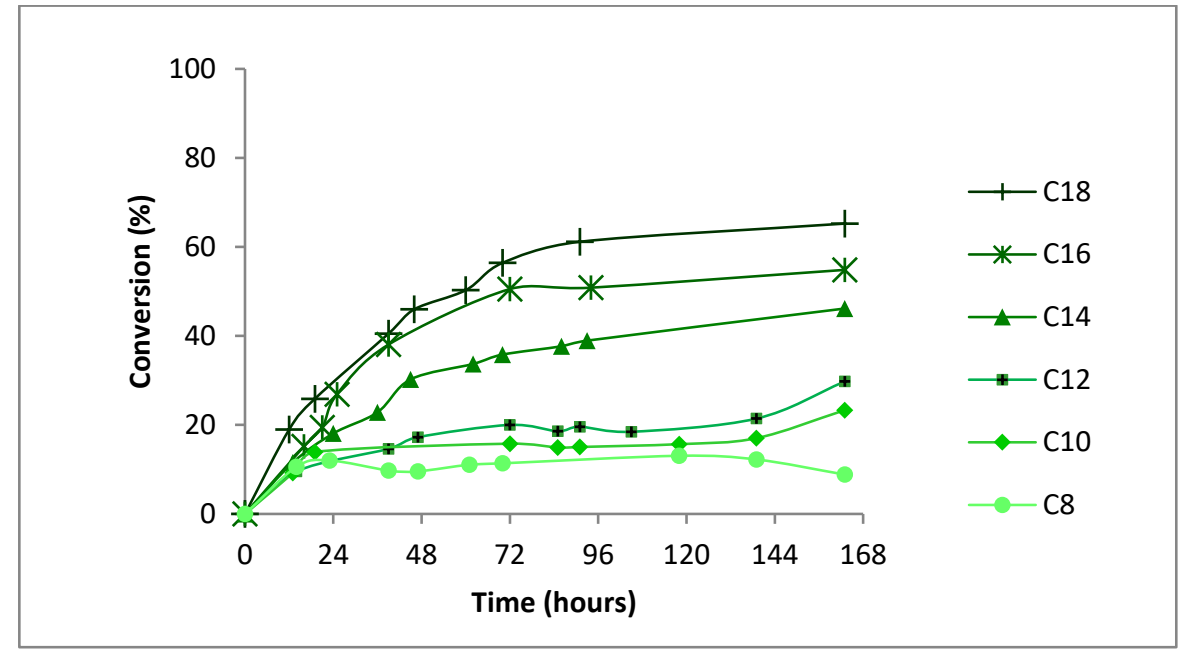

Figure 1 : Effect of the fatty acid chain length on glucoester synthesis

Whatever the FA used, glycolipid was produced although the formed water was not removed to shift the equilibrium. After 168 hours of reaction, only the $\mathrm{C} 8$ plot seems to have reached the equilibrium, while conversions into other glucoesters are still slightly increasing. Conversions, as well as initial rate, increased with FA chain length. This preference of CALB for longer chains, which are more hydrophobic, is not very surprising as CALB exhibits a hydrophobic elliptical, steep funnel of 9.5×4.5 Å active site. (24) Those results are consistent with those published by Ghoul and coll. (17) On the contrary, as already mentioned, Pedersen and coll. observed the opposite trend on the esterification of disaccharides. (20) In that case, the size of the disaccharides probably hinders the FA access to the active site, short chain FAs accessing more easily the active site than the long chain FAs. 


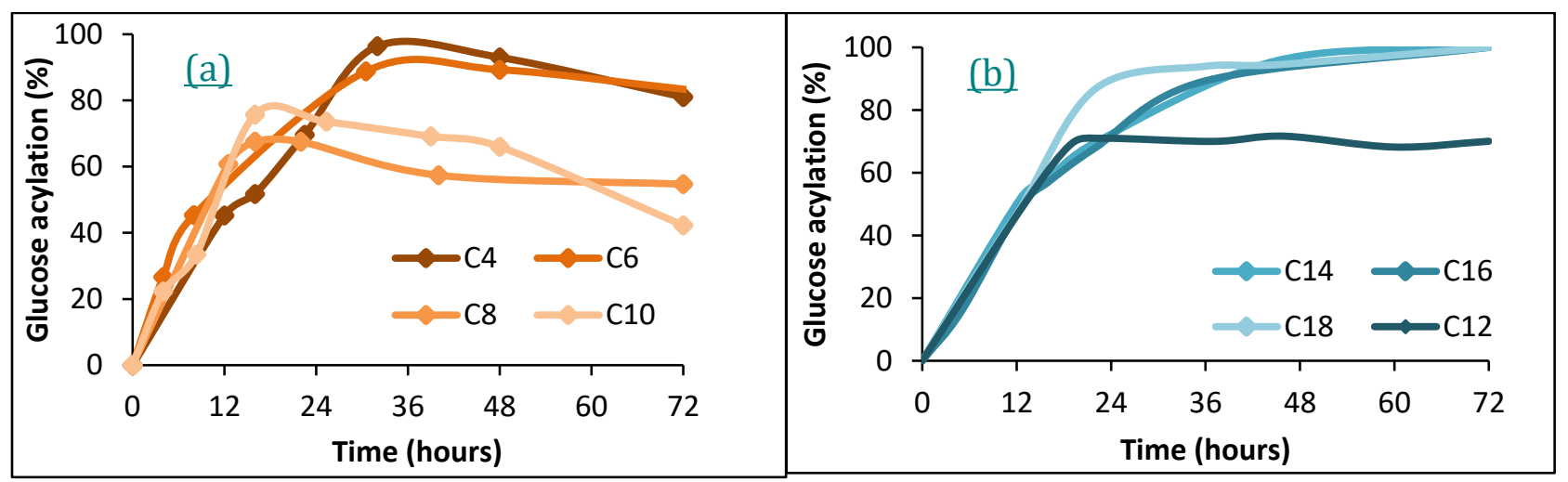

Figure 2: Kinetics of FAVEs conversion into glucoesters determined by ${ }^{1} \mathrm{H}$ NMR: effect of FAVEs chain length ; (a) left $=\mathrm{C} 4$ to C10 FAVEs; (b) right $=$ C12 to C18 FAVEs

As already observed with fatty acids, the best conversions were obtained for the long chain FAVEs (C14, C16 and C18). In the case of C18, the conversion into glycolipid was even total. More surprisingly, conversions up to 90-95\% were reached with C4 and C6 FAVEs. Lower conversion rates were obtained for $\mathrm{C} 8, \mathrm{C} 10$ and $\mathrm{C} 12$, with a minimum conversion of $42 \%$ for $\mathrm{C} 10$. For FAVE with the largest chain lengths (C12 to C18), FASE concentrations increase linearly with time at a very similar conversion rate (Table 1). Whereas C12 FASE concentration reached a conversion of 75 $\%$ after 72 hours, full conversion into FASEs was observed with all other long-chain FAVEs. For the shortest FAVE chains (C4 to C10), FASE concentration reaches an optimum and then decreases slowly with time.

The variation of FAVE, FA and FASE with time for FAVEs with chain lengths from C8 to C18 is shown in Figure 3. Because of the volatility of FAVE and FA with the shortest chains, it was not possible to obtain accurate data for $\mathrm{C} 4$ and C6 FAVEs. For all chain lengths, FAVE conversion into both FASE and FA strongly prevailed. When all the FAVE was consumed (most of the time in $24 \mathrm{~h}$ ), only the reversible reaction between FA and FASE remained. Nevertheless, depending on the chain length, two different behaviors could be observed. For C12, C14, C16 and C18 FAVEs, the equilibrium is shifted toward FASE formation. Total consumptions of FAs were observed for C14, C16 and C18, while C12 glucoester, was much slower and was still ongoing after 72 hours. For C8 
and C10 FAVEs, the equilibrium is shifted to the FA formation and FASE is slowly hydrolyzed. In all cases, FAVE trans-esterification allows reaching much higher glucose acylation rates than FA direct esterification (See Table 1).
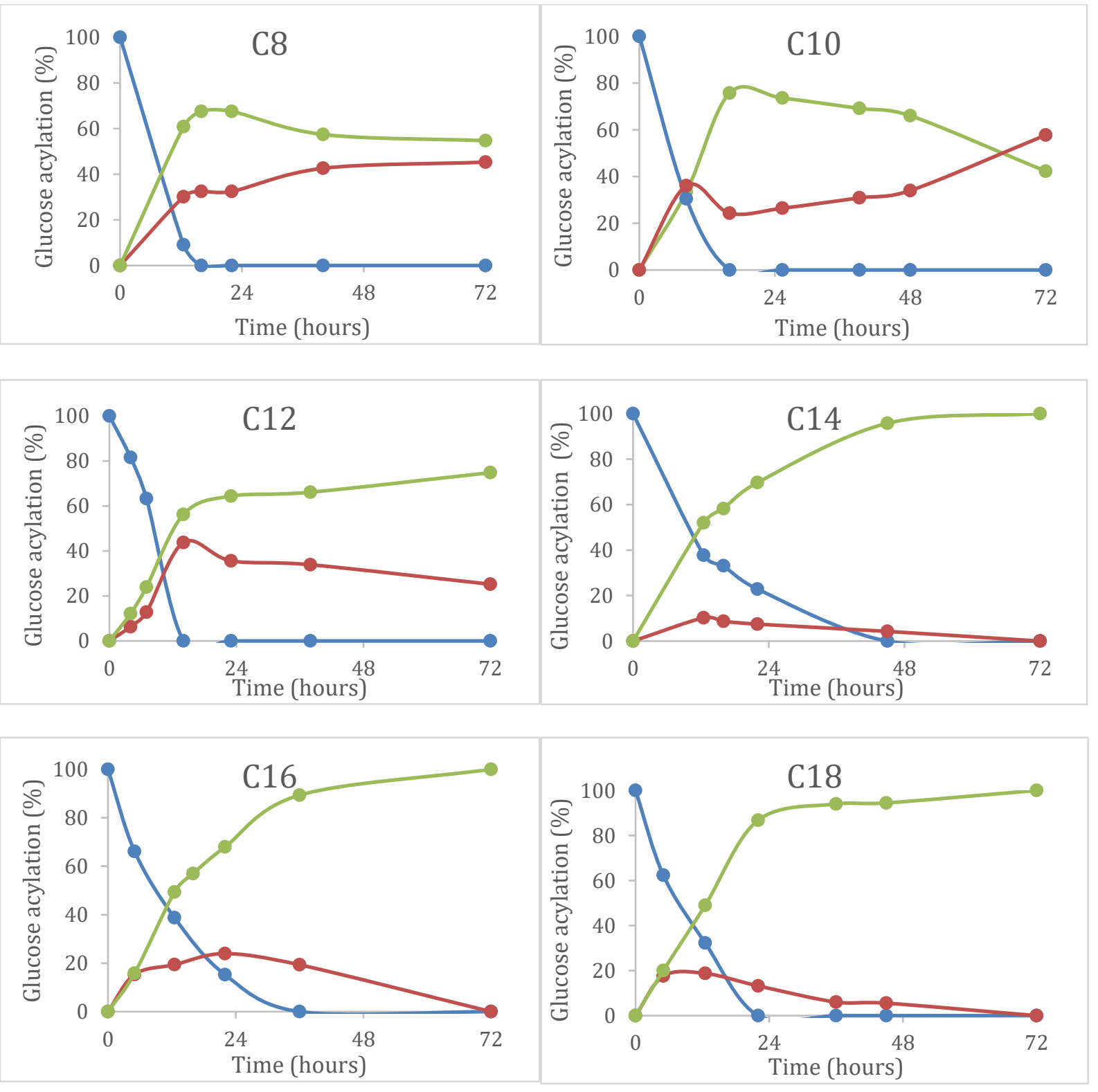

Figure 3: Variation of FAVE, FA and glucoester contents for FAVEs from C8 to C18 determined by ${ }^{1}$ H NMR. Blue = FAVE $;$ Red = FA ; Green = glucoester

In order to explain those results, maximal FASE solubilities for C10 to C18 chains in acetonitrile at $25^{\circ} \mathrm{C}$ have been determined by HPLC (See Table 2 and supplementary information). Indeed, 
Schmid and coll. observed that the longer the FA chain, the less soluble the corresponding glucoester. $(18 ; 19)$ Saturated glucoesters show very poor solubility in acetonitrile; precipitation of longchain glucoesters could then shift the equilibrium and lead to higher conversions than for short chain FAs.

\begin{tabular}{|c|c|c|c|}
\hline FASE & Maximal solubility $(\mu \mathrm{mol} / \mathrm{mL})$ & Highest FASE amount measured ( $\mu \mathrm{mol} / \mathrm{mL})$ \\
& & From FA & From FAVE \\
\hline C4 & - & - & 86.7 \\
\hline C6 & - & 8.0 & 80.4 \\
\hline C8 & 23.6 & 26.7 & 60.8 \\
\hline C10 & 6.85 & 26.8 & 68.1 \\
\hline C12 & 1.99 & 41.5 & 67.3 \\
\hline C14 & 0.60 & 49.3 & 90.0 \\
\hline C16 & 0.26 & 58.7 & 90.0 \\
\hline C18 & & & \\
\hline
\end{tabular}

Table 2 - Maximal FASEs solubilities in acetonitrile at $25^{\circ} \mathrm{C}$ compared to FASEs highest measured concentrations during esterification and trans-esterification reactions

Solubilities decrease from 23.6 to $0.26 \mu \mathrm{mol} / \mathrm{mL}$ while increasing the chain length from $\mathrm{C} 10$ to $\mathrm{C} 18$. On another hand, FASE amounts go from 8.0 to $58.7 \mu \mathrm{mol} / \mathrm{mL}$ during direct esterification reactions, and from 60.8 to $90.0 \mu \mathrm{mol} / \mathrm{mL}$ during FASE trans-esterification reactions. As C10 glucoester maximal solubility is higher than the others, starting from C4 to C10 FAVEs, even if a fraction of formed glucoesters could precipitate out of the reactional medium, a significant part remains in solution. As they are smaller molecules than C12 to C18 glucoesters, they are mobile enough to access the CALB active site and therefore be hydrolyzed, (See Scheme 2) causing a decrease of measured conversion. Starting from C8 and C10 FAs, their esterification rates being 
significantly lower, it could be assumed that all the so-formed glucoesters remains in solution. In that case, the system converges to the thermodynamic equilibrium. On the opposite, starting for C12 FAs or FAVEs and higher, almost all the so-formed glucoesters precipitate out of the reaction medium, shifting the equilibrium into their formation. As only a tiny amount of glucoesters remains in solution, there is no hydrolysis occurring.

\subsection{Influence of unsaturations}

As the best results were obtained with vinyl stearate, the influence of double bonds was investigated with unsaturated $\mathrm{C} 18$ vinyl esters: vinyl oleate (vinyl cis-9-octadecenoate, C18:1), vinyl elaidate (vinyl trans-9-octadecenoate, C18:1T), vinyl linoleate (vinyl cis-9,cis-12-octadecadienoate, C18:2), and vinyl linoleaidate (vinyl trans-9,trans-12-Octadecadienoate, C18:2TT). Enzymatic transesterifications of those FAVEs were monitored by ${ }^{1} \mathrm{H}$ NMR. In all cases, all the FAVEs were transformed into FAs and/or FASEs, (See Scheme 3) and the reaction equilibrium between the glycolipid and the fatty acid was reached after 24 hours (See Figure 4). Both conversion into glycolipid and initial conversion rate were higher for trans FAVEs than for cis FAVEs and they both decreased with increasing number of double bonds. For vinyl linoleate, only traces of glycolipid were detected (See Table 3).

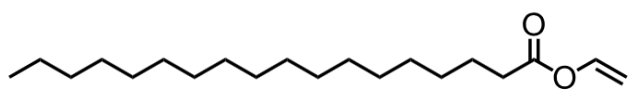

C18:0

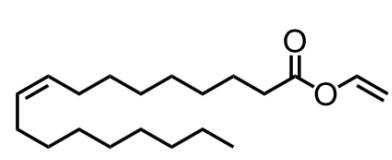

C18:1

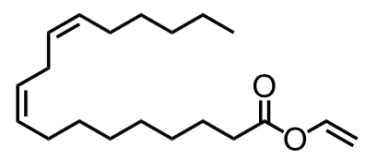

C18:2

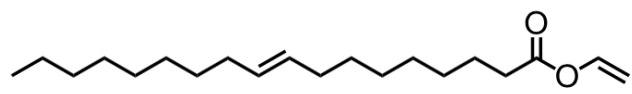

C18:1T

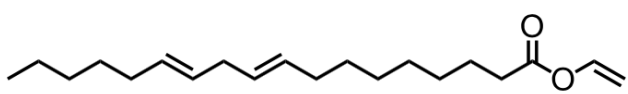

C18:2TT

Scheme 3 : C18 FAVEs: C18:0 = vinyl stearate ; C18:1 = vinyl oleate ; C18:2 = vinyl linoleate ; C18:1T = vinyl elaidate $;$ C18:2TT $=$ vinyl linoleaidate 


\begin{tabular}{|l|l|l|l|l|l|}
\hline FAVE & $\mathrm{C} 18: 0$ & $\mathrm{C} 18: 1 \mathrm{~T}$ & $\mathrm{C} 18: 2 \mathrm{TT}$ & $\mathrm{C} 18: 1$ & $\mathrm{C} 18: 2$ \\
\hline Conversion & $100 \%$ & $83 \%$ & $70 \%$ & $47 \%$ & $<5 \%$ \\
\hline $\begin{array}{l}\text { Initial conversion rate } \\
\left(\mu \text { mol.min }^{-1} \cdot \mathbf{g}^{-1} \text { lipase }\right)\end{array}$ & 29,6 & 26,0 & 18,3 & 17,1 & - \\
\hline
\end{tabular}

Table 3 : Influence of the number and the configuration of unsaturations on FAVE conversion into glucoester. Initial conversion rate into 6-O-glucose linoleate was too low to be calculated

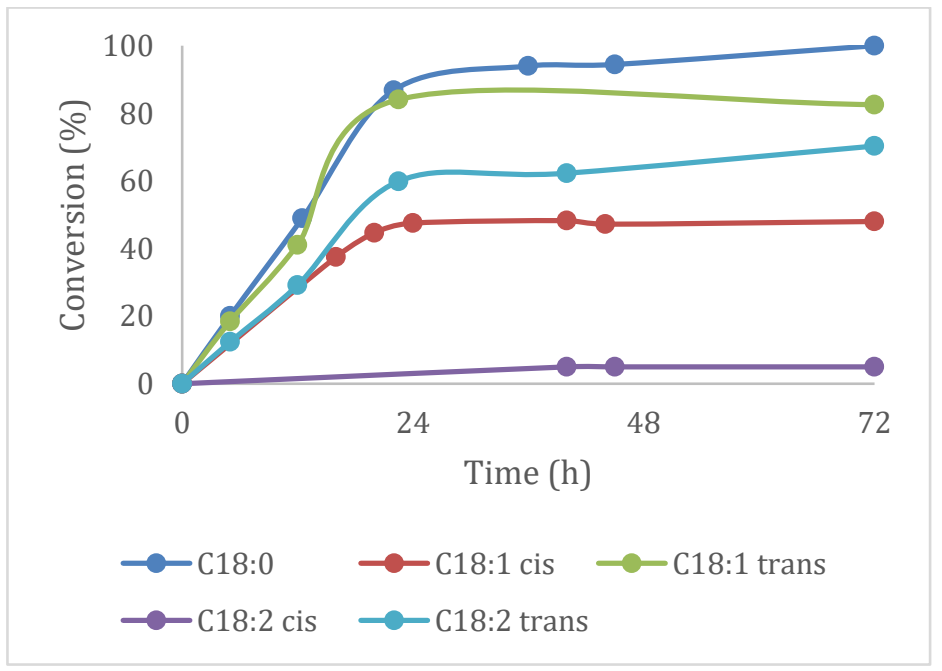

Figure 4 : Influence of the number and configuration of unsaturations on FAVE conversion into glucoester

Cis configuration seems to cause steric hindrance, making the FAVE access to the enzyme active site more difficult and thus decreasing a lot the formation of FASE. The lower decrease observed for C18:1T and C18:2TT can be due to the reduction of the chain mobility because of the presence of double bonds. Again, contradictory results can be found in the literature. Indeed, in the case of flavonoids esterification with oleic, linoleic and linolenic acids, conversions of 70, 80 and 68\% were respectively obtained at $50^{\circ} \mathrm{C}$ in acetone, showing almost no influence of the number of unsaturations. 
(25) Ardhaoui et al. also scarcely found a difference of behavior between stearic acid and oleic acid for flavonoid esterification. (26) In both cases, a huge amount of lipase was used (0.7 to $1.2 \mathrm{~g}$ of CALB per mmol of flavonoid) whereas, in this study, only $22 \mathrm{mg}$ of CALB per mmol of glucose was employed. It could be assumed that, in their case, the influence of unsaturations could have been smoothed by the important quantity of catalyst. On the contrary, Hollman et al. (27) studied the influence of a methyl substituent in valeric acid on the rate of CALB-catalyzed esterification of 1octanol and found that it strongly decreased for 2- and 3-methyl valeric acids. Lin et al. found similar results comparing esterification of acetoin with linear and branched fatty acids. (28) These results show the importance of the substrate geometry to obtain high conversions into glycolipid: a saturated, linear fatty acid will easily access to the enzyme active site while hindrance caused by unsaturations will lead to lower conversions.

\section{Conclusion}

In this paper, the influence of the acyl donor type and geometry (fatty acid or vinyl ester with chain lengths from 4 to 18 carbons, saturated or unsaturated) on the enzymatic synthesis of glucose-based FASEs were investigated. From both types of acyl donors, CALB showed more affinity for alkyl chains longer than 12 carbons. Starting from fatty acids, an equilibrium between FA and FASE is reached within 4 days. Higher glucose acylation rates were obtained with FAVEs, as the continuous natural elimination of so-formed acetaldehyde allows the reaction system to exceed equilibrium, and maximum FASE concentrations were reached within 16 to 32 hours. The presence of unsaturation on the fatty chain was showed to hinder the access of the enzyme active site, causing lower acylation rates.

\section{References}


1. T Raku, M Kitagawa, H Shimakawa, and Y Tokiwa, Enzymatic synthesis of hydrophylic undecylenic acid sugar esters and their biodegradability. 2003, Biotechnology Letters, Vol. 25 (2), pp. 161-166.

2. T Raku, M Kitagawa, H Shimakawa, and Y Tokiwa, Enzymatic synthesis of trehalose esters having liphophilicity. Journal of Biotechnology, Vol. 100, pp. 203-208.

3. Y Queneau, S Jarosz, B Lewandowski, and J Fitremann, Sucrose chemistry and application of sucrochemicals, Adv. Carbohydr. Chem. Biochem., Vol. 61 (7), pp. 217-292.

4. I M Banat, A Franzetti, I Gandolfi, G Bestetti, M G Martinotti, L Fracchia, T J Smyth, and R Marchant, Microbial biosurfactants production, applications and future potential. 2010, Appl. Microbiol. Biotechnol., Vol. 87 (2), pp. 427-444.

5. P J Hall, J Haverkamp, C G van Kralingen, and M Schmidt, Laundry detergent composition containing synergistic combination of sophorose lipid and nonionic surfactant. 5520839 US, 1996.

6. N R Khan and V K Rathod, Enzyme catalyzed synthesis of cosmetic esters and its intensification: A review. 2015, Process Biochemistry, Vol. 50 (11), pp. 1793-1806.

7. Lourith N. and Kanlayavattanakul M., Natural surfactants used in cosmetics: glycolipids2009, Int. J. Cosmet. Sci., Vol. 31 (4), pp. 255-261.

8. A Asghar, F Muhammad Anjum and J C Allen, Utilization of dairy byproduct proteins, surfactants, and enzymes in frozen dough. 2011, Critical Reviews in Food Science and Nutrition, Vol. 51 (4), pp. 374-382.

9. A Sampaio, J. Leiton and S. D. Oliveira Enzymatic synthesis of sugar esters and their potential as surface-active stabilizers of coconut milk emulsions. 2012, Food Hydrocoll., Vol. 27 (2), pp. 324-331.

10. S-W Hsieh, M-R Lee, C-W Tsai, L-Y Lai, T Yeh, C-W Hsieh, T-J Yang, and S-W Chang, Enzymatic synthesis, purification and identification of bioactive trehalose ester derivatives for health applications. 2015, Food and Bioproducts Processing,Vol. 95, pp. 163-172. 
11. M Habulin, S Sabeder and Z Knez, Enzymatic synthesis of sugar fatty acid esters in organic solvent and in supercritical carbon dioxide and their antimicrobial activity. 2008, The Journal of Supercritical Fluids, Vol. 45, pp. 338-345.

\section{M Ferrer, J Soliveri, F J Plou, N López-Cortés, D Reyes-Duarte, M Christensen, J L}

Copa-Patiño and A Ballesteros, Synthesis of sugar esters in solvent mixtures by lipases from Thermomyces lanuginosus and Candida antarctica B, and their antimicrobial properties. 2005, Enzyme and Microbial Technology, Vol. 36 (4), pp. 391-398.

\section{T Watanabe, S Katayama, M Matsubara, Y Honda, M Kuwahara, Antibacterial} carbohydrate monoesters suppressing cell growth of Streptococcus mutans in the presence of sucrose, 2000, Curr. Microbiol, Vol. 41 (3), pp. 210-213.

14. G John, G Zhu, J Li, and J S Dordick, Enzymatically derived sugar-containing selfassembled organogels with nanostructured morphologies, 2006, Angewandte Chemie International Edition, Vol. 45, pp. 4772-4775.

15. C C Akoh and B G Swanson, Synthesis and properties of alkyl glycoside and stachyose fatty acid polyesters.. 1989, JAOCS, Vol. 66(9), pp. 1295-1301.

16. S Soultani, JM Engasser and M Ghoul, Effect of acyl donor chain length an sugar/acyl donor molar ration on enzymatic synthesis of fatty acid fructose esters. 2001, J. Mol. Cat. B: Enzymatic, Vol. 11, pp. 725-731.

17. L Cao, U T Bornsheuer and R D Schmid, Lipase-catalyzed solid-phase synthesis of sugar esters, IV: selectivity of lipases towards and secondary hydroxyl groups in carbohydrates. 1998, Biocatalysis and Biotransformation, Vol. 16 (4), pp. 249-257.

18. L Cao, U T Bornscheuer, and R D Schmid, Lipase-catalyzed solid phase synthesis of sugar esters. 1996, Lipid/Fett, Vol. 98 (10), pp. 332-335.

19. N R Pedersen, R Wimmer, J Emmersen, P Degn, and L H Pedersen, Effect of fatty acid chain lenght on initial reaction rates and regioselectivity of lipase-catalyzed esterification of dissacharides, 2002, Carbohydrate Reasearch, Vol. 337 (13), pp. 1179-1184. 
20. Y-M Xiao, Q Wu, Y Cai, and X-F Lin, Ultrasound-accelerated enzymatic synthesis of sugar esters in nonaqueous solvents, 2005, Carbohydrate Research, Vol. 340 (13), pp. 2097-2103.

21. D Arcens, E Grau, S Grelier, H Cramail, and F Peruch, 6-O-glucose palmitate synthesis with lipase : Investigation of some key parameters. 2018, Molecular Catalysis, Vol. 460, pp. 63-68 22. C Vilela, R Rua, A J DSilvestre, and A Gandini, Polymers and copolymers from fatty acidbased monomers, 2010 , Industrial Crops and Products, Vol. 32, pp. 97-104.

23. Y Wang, JJ Lalonde, and C Wong, Lipase-catalyzed irreversible transesterifications using enol A. 1988, J. Chem. Soc., Vol. 100 (6), pp. 7200-7205.

24. J Pleiss and M S R Fisher, Anatomy of lipase binding sites : the scissile fatty acid binding site. 1998, Vol. 93, pp. 67-80.

25. F Mellou, H Loutrari, H Stamatis, C Roussos, and F N Kolisis, Enzymatic esterification of flavonoids with unsaturated fatty acids: Effects of the novel esters on vascular endothelial growth factor release from K562 cells, 2006, Process Biochemistry, Vol. 41, pp. 2029-2034.

26. M Ardhaoui, A Falcimaigne, J-M Engasser, P Moussou, G Pauly, and M Ghoul, Acylation of natural flavonoids using lipase of cadida antarctica as biocatalyst, 2004, J. Mol. Cat. B:

Enzymatic, Vol. 29, pp. 63-67.

27. F Hollmann, P Grzebyk, V Heinrichs, K Doderer, and O Thum, On the inactivity of Candida antarctica lipase B toward strong acids, 2009, J. Mol. Cat. B: Enzymatic, Vols. 57 (1-4), pp. 257-261.

28. Z Xiao, X Hou, X Lyu, J-Y Zhao, L Xi, J Li and J R Lu, Enzymatic synthesis of aroma acetoin fatty acid esters by immobilized Candida antarctica lipase B, 2015, Biotechnology Letters, Vol. 37 (8), pp. 1671-1677. 


\section{Effect of the nature of fatty acid on CALB-catalyzed esterification of glucose}

Dounia Arcens ${ }^{\mathrm{a}}$, Etienne Grau ${ }^{\mathrm{a}}$, Stéphane Grelier ${ }^{\mathrm{a}}$, Henri Cramail*a and Frédéric Peruch*a

${ }^{a}$ Univ. Bordeaux, CNRS, Bordeaux INP, LCPO, UMR 5629, F-33600, Pessac, France

e-mail: peruch@enscbp.fr ; cramail@enscbp.fr

\section{Supplementary information}

1. Calculation of conversions into FASE based on ${ }^{1} \mathrm{H}$ NMR spectra: example of 6-O-glucose palmitate:

${ }^{1} \mathrm{H}$ NMR spectra of vinyl palmitate, palmitic acid, 6-O-glucose palmitate, glucose and crude mixture after 16 hours of reaction are plotted in Figure S1. Attributions have been checked by COSY, HSQC and HMBC NMR. All signals and their attributions are plotted in Table S1. Vinyl palmitate, palmitic acid and 6-O-glucose palmitate contents have been calculated using Equation S1.

$$
\begin{aligned}
& \% V P \\
& =\frac{\frac{1}{2} *\left(0.5 I_{2.41 \mathrm{ppm}}+I_{7.21 \mathrm{ppm}}\right)}{\frac{1}{2} *\left(0.5 I_{2.41 \mathrm{ppm}}+I_{7.21 \mathrm{ppm}}\right)+\frac{1}{2}\left(0.5 I_{2.17 \mathrm{ppm}}+I_{11.93 \mathrm{ppm}}\right)+\frac{1}{7} *\left(0.5 I_{2.26 \mathrm{ppm}}+I_{3.76 \mathrm{ppm}}+I_{3.99 \mathrm{ppm}}+I_{5.01 \mathrm{ppm}}+I_{5.07 \mathrm{ppm}}+I_{6.33 \mathrm{ppm}}+I_{6.64 \mathrm{ppm}}\right)} \\
& \% P A \\
& =\frac{\frac{1}{2}\left(0.5 I_{2.17 p p m}+I_{11.93 \mathrm{ppm}}\right)}{\frac{1}{2} *\left(0.5 I_{2.41 \mathrm{ppm}}+I_{7.21 \mathrm{ppm}}\right)+\frac{1}{2}\left(0.5 I_{2.17 \mathrm{ppm}}+I_{11.93 \mathrm{ppm}}\right)+\frac{1}{7} *\left(0.5 I_{2.26 \mathrm{ppm}}+I_{3.76 \mathrm{ppm}}+I_{3.99 \mathrm{ppm}}+I_{5.01 \mathrm{ppm}}+I_{5.07 \mathrm{ppm}}+I_{6.33 \mathrm{ppm}}+I_{6.64 \mathrm{ppm}}\right)} \\
& \text { \%GP } \\
& =\frac{\frac{1}{7} *\left(0.5 I_{2.26 p p m}+I_{3.76 p p m}+I_{3.99 p p m}+I_{5.01 p p m}+I_{5.07 p p m}+I_{6.33 p p m}+I_{6.64 p p m}\right)}{\frac{1}{2} *\left(0.5 I_{2.41 p p m}+I_{7.21 p p m}\right)+\frac{1}{2}\left(0.5 I_{2.17 p p m}+I_{11.93 p p m}\right)+\frac{1}{7} *\left(0.5 I_{2.26 p p m}+I_{3.76 p p m}+I_{3.99 p p m}+I_{5.01 p p m}+I_{5.07 p p m}+I_{6.33 p p m}+I_{6.64 p p m}\right)}
\end{aligned}
$$

Equation S1: Calculation of vinyl palmitate (VP), palmitic acid (PA), and 6-O-glucose palmitate (GP) percentages of a given crude sample. I represents the integral value for each signal on the corresponding NMR spectrum. Integrals were calculated by setting $\mathbf{I}_{0.85} \mathrm{ppm}=3$ 


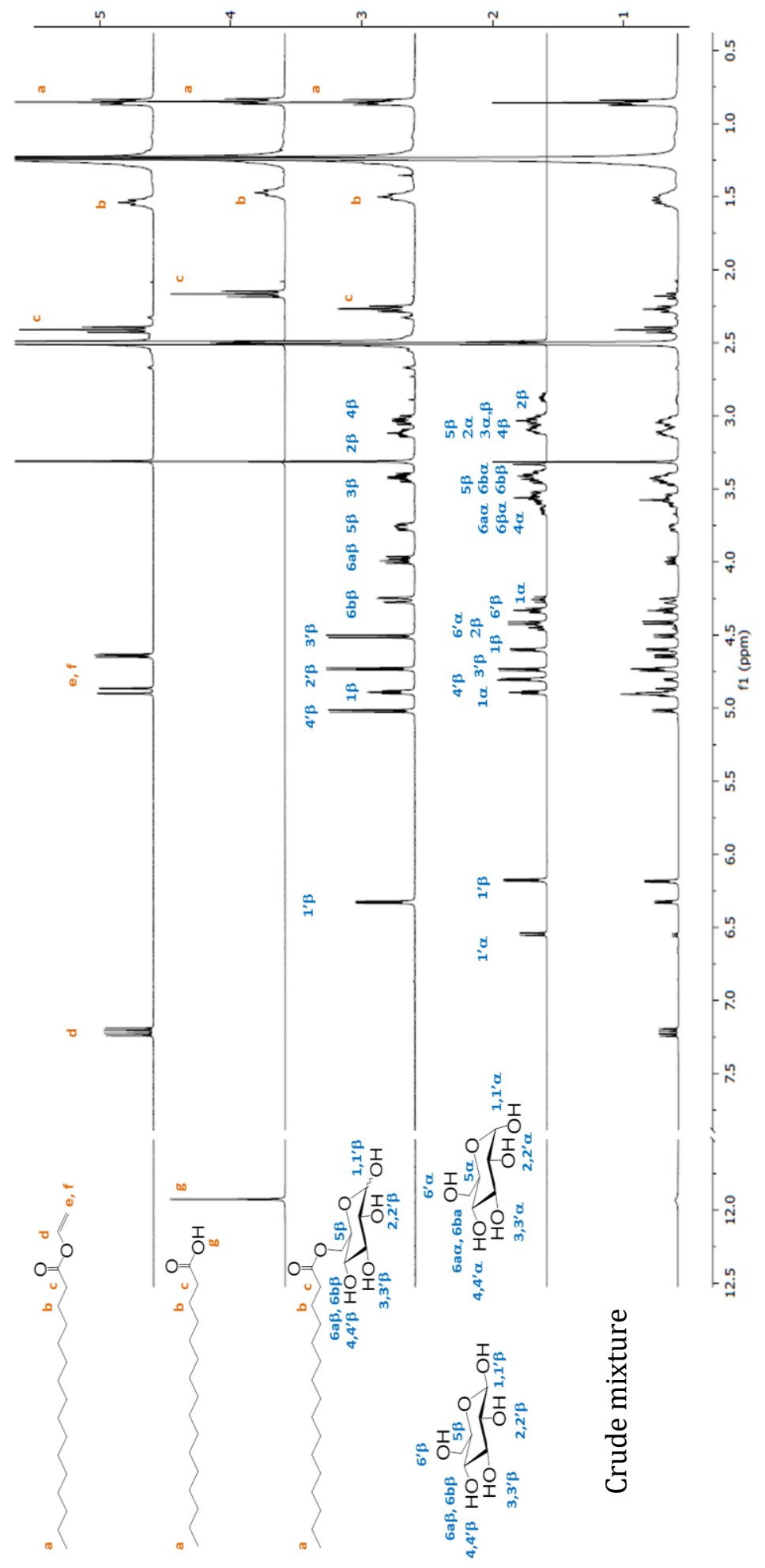

Figure S1: Stacked ${ }^{1} \mathrm{H}$ NMR spectra of (from top to bottom) pure vinyl palmitate, pure palmitic acid, pure 6-O-glucose palmitate, pure glucose, and crude reaction mixture after $16 \mathrm{~h}$ 
(conditions: vinyl palmitate/glucose molar ratio $=1 / 1$, concentration $=90 \mathrm{mM}, 5 \%$ of CALB $(20 \mathrm{mg})$, in $10 \mathrm{~mL}$ of anhydrous acetonitrile; reaction performed at $45^{\circ} \mathrm{C}$ )

Table S1: List of chemical shifts on a typical raw mixture of vinyl palmitate, palmitic acid, glucose and 6-O-glucose palmitate

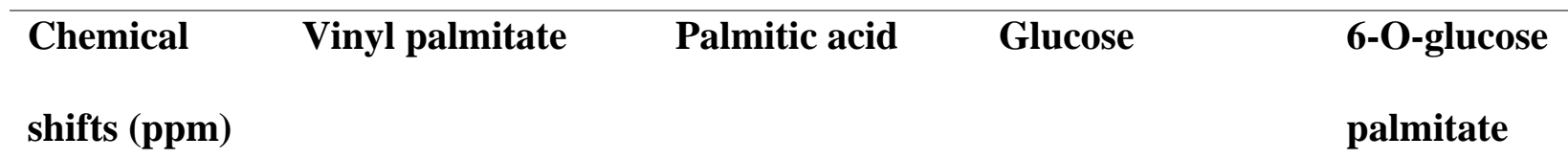

\begin{tabular}{lll}
\hline $\mathbf{0 . 8 5}$ & $\mathrm{CH}_{3}$ & $\mathrm{CH}_{3}$
\end{tabular}

$\begin{array}{lllll}\text { 1.14-1.34 } & \mathrm{CH}_{2} & \text { alkyl } & \mathrm{CH}_{2} \text { alkyl chain } & \mathrm{CH}_{2} \text { alkyl chain }\end{array}$
chain

\begin{tabular}{lllc}
\hline $\mathbf{1 . 5 4}$ & $\mathbf{C H}_{2}-\mathrm{CH}_{2}-\mathrm{CO}$ & $\mathbf{C H}_{2}-\mathrm{CH}_{2}-\mathrm{CO}$ & $\mathbf{C H}_{2}-\mathrm{CH}_{2}-\mathrm{CO}$ \\
\hline $\mathbf{2 . 1 7}$ & $\mathbf{C H}_{2}-\mathrm{CO}$ & \\
\hline $\mathbf{2 . 2 6}$ & & $\mathbf{C H}_{2}-\mathrm{CO}$
\end{tabular}

2.41

2.89

$\mathrm{H} 2 \beta$

3.04

H4

3.10

H2

3.42

$\mathrm{H} 5 \alpha, \mathrm{H} 6 \mathrm{~b} \alpha, \mathrm{H} 6 \mathrm{~b} \beta \quad \mathrm{H} 3$

3.57

$\mathrm{H} 4 \alpha, \mathrm{H} 6 \mathrm{a} \beta$

3.66

H6a $\alpha$

\begin{tabular}{ll}
\hline 3.76 & H5
\end{tabular}

3.99 H6a

$4.26 \quad H 1 \beta \quad$ H6b

$4.33+H 6 ’ \beta$

4.41

$\mathrm{H} 2^{\prime} \beta$ 


\subsection{5}

$H 6^{\prime} \alpha$

\subsection{0}

4.56

$4.60 \quad H 3$ ' $\beta$

4.73

H3'

\begin{tabular}{ll}
\hline $\mathbf{4 . 7 4}$ & $\mathrm{H} 4^{\prime} \beta$ \\
\hline $\mathbf{4 . 8 0}$ & $\mathrm{H}^{\prime}{ }^{\prime} \alpha, \mathrm{H} 3^{\prime} \alpha, \mathrm{H} 4^{\prime} \alpha$
\end{tabular}

$4.86 \quad \mathrm{CH}_{2}=\mathrm{CH}$

4.90

$\mathrm{H} 1 \alpha$

H1

5.01

H4' $\beta$

5.07

$H^{4}$ ' $\alpha$

\subsection{8}

H1' $\beta$

6.33

H1' $\beta$

6.55

$\mathrm{H} 1^{\prime} \alpha$

6.64

$H 1^{\prime} \alpha$

\subsection{1 \\ $\mathbf{C H}=\mathrm{CH}_{2}$}

\subsection{3}

$\mathrm{COOH}$

\section{Determination of FASEs solubilities by HPLC}

HPLC conditions are given in the Materials and Methods section

For each FASE, a calibration curve for glucose was determined by injecting in HPLC samples from six FASE solutions in DMSO at known concentrations. (See Figure S2) For each sample, peak areas were measured and the obtained values were plotted versus injected mass. The relation between measured areas $\left(\mathrm{Acn}_{\mathrm{Cn}}\right)$ and corresponding glucose mass $\left(\mathrm{mcn}_{\mathrm{n}}\right)$ was obtained by linear regression. 

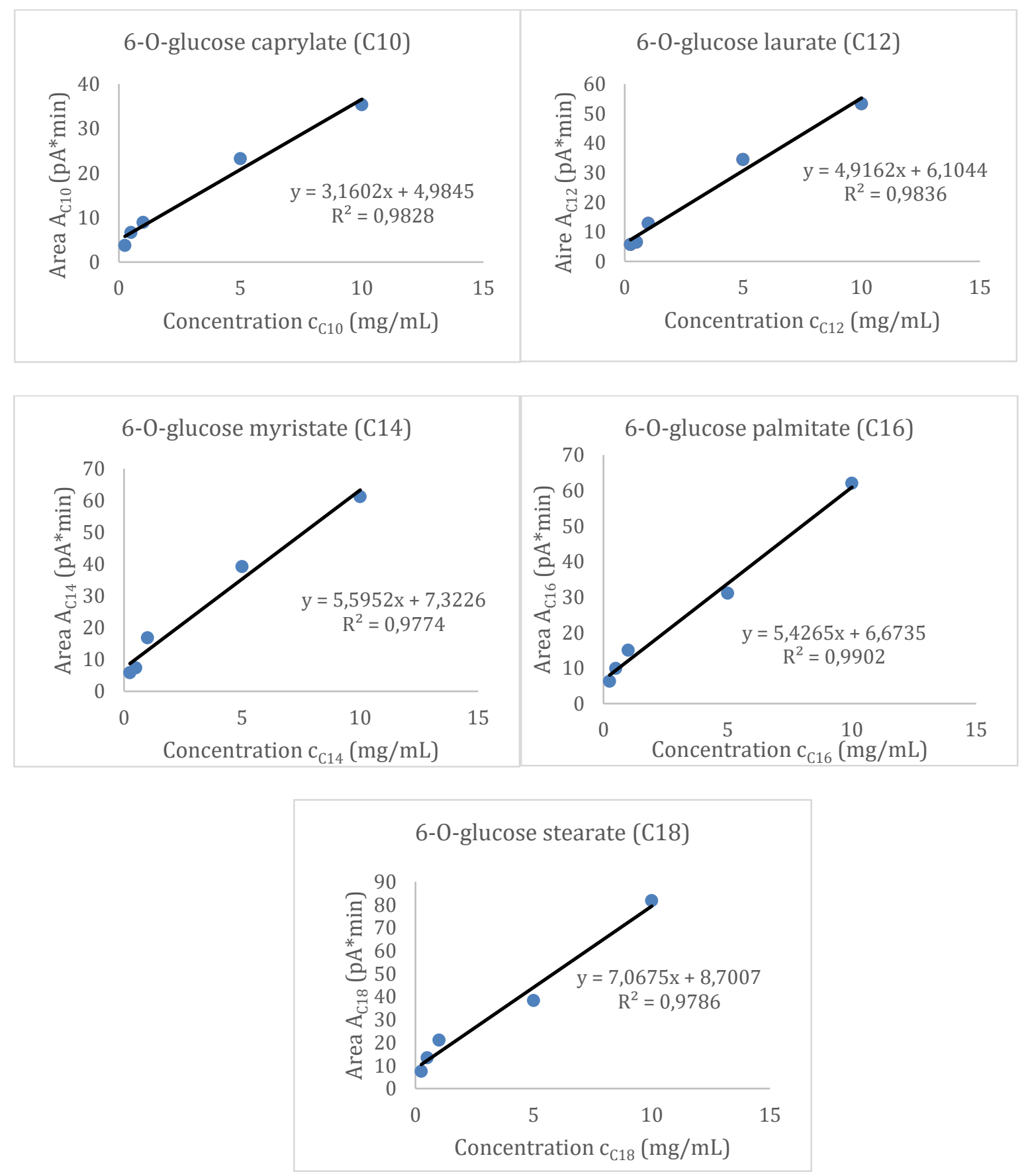

Figure S2 - Calibration curves for FASEs from C10 to C18

Determination of FASEs maximal solubilities in acetonitrile

An excess of each FASE was put in a capped glass vial containing a magnetic bar, in presence of 1 $\mathrm{mL}$ of acetonitrile. All the vials were put under agitation in a thermostated oil bath at $25^{\circ} \mathrm{C}$ for 72 hours. The samples were filtrated on $0.4 \mu \mathrm{m}$ cellulose filters to remove insoluble FASE and the 
soluble parts were analyzed by HPLC. For each sample, the FASE peak area was measured and the corresponding concentration was calculated using the previously plotted calibration curves. All results are plotted in Table S2.

\begin{tabular}{ccccc}
\hline FASE & Injected & Area & \multicolumn{2}{c}{ Concentration } \\
& volume $(\mu \mathbf{L})$ & $(\mathbf{p A} * \mathbf{m i n})$ & $\mathbf{m g} / \mathbf{m L}$ & $\mu \mathbf{m o l} / \mathbf{m L}$ \\
& & & & \\
\hline $\mathbf{C 1 0}$ & 50 & 16.720 & 5.29 & 26.7 \\
\hline $\mathbf{C 1 2}$ & 50 & 7.646 & 1.56 & 6.85 \\
\hline $\mathbf{C 1 4}$ & 50 & 2.827 & 0.51 & 1.99 \\
\hline $\mathbf{C 1 6}$ & 50 & 1.061 & 0.17 & 0.60 \\
\hline $\mathbf{C 1 8}$ & 50 & 0.564 & 0.08 & 0.26
\end{tabular}

Table S2. C10, C12, C14, C16 and C18 FASE maximal solubilities in acetonitrile at $25^{\circ} \mathrm{C}$ 